\title{
Resistência antimicrobiana nos animais e no ser humano. Há motivo para preocupação?
}

\section{Antimicrobial resistance in animals and in human being. There is reason for concern?}

\author{
Mônica Vicky Bahr Arias ${ }^{1 *}$; Cláudia Maria Dantas de Maio Carrilho
}

\section{Resumo}

\begin{abstract}
A resistência aos agentes antimicrobianos tornou-se uma das principais preocupações para a saúde humana, mas também está se tornando problema em medicina veterinária. Os antimicrobianos são usados mundialmente para tratamento e profilaxia de doenças infecciosas em animais de produção, equinos e animais de companhia e como promotores de crescimento. Em muitos estudos observou-se que o uso de antimicrobianos em animais contribuiu para o desenvolvimento de resistência antimicrobiana em humanos, pois muitas classes de antimicrobianos usadas em animais também são empregadas em seres humanos para tratar doenças graves, ocorrendo falha terapêutica, devido à transferência de bactérias resistentes pela cadeia alimentar. Alguns autores questionam se este risco para a saúde pública originouse somente do uso de antimicrobianos em animais, visto que estas substâncias são usadas na agricultura e também são encontradas naturalmente no meio ambiente. Assim a resistência bacteriana pode se desenvolver mesmo sem o uso de antimicrobianos. Logo, neste artigo, busca-se revisar o papel dos animais na transmissão de bactérias resistentes aos seres humanos e vice-versa questionando ainda a existência de outras fontes de resistência.
\end{abstract}

Palavras-chave: Antimicrobianos, bactérias, resistência às drogas, animais, medicina humana

\begin{abstract}
Resistance to antimicrobial agents has become one of the main concerns for human health, but has also become a problem in veterinary medicine. Antimicrobial agents are used worldwide in veterinary practice for therapy and prophylaxis of infectious diseases in food, horses and companion animals and for growth promotion in food animals. Many studies have shown that this kind of antimicrobial use in animals contributed to the selection of antimicrobial resistance, because many classes of antibiotics used in animals are used to treat serious diseases in humans, causing therapeutic failure, because of transference of resistant bacteria through food chain. Some authors question if this hazard to public health originated only from the use of antibiotic in animals, since these substances are also used in agriculture and are naturally found in the environment. So the antimicrobial resistance may develop even without the use of antibiotics. Therefore, the present article reviews the role of animals in the transmission of resistant bacteria to humans and vice versa, and questions about the existence of others sources of resistance.
\end{abstract}

Key words: Antibacterial agents, bacteria, drug resistance, animals, human medicine

\footnotetext{
1 Médica Veterinária, Mestre e Doutora em Cirurgia pela FMVZ-USP, Prof ${ }^{\mathrm{a}}$ Associada do Dept ${ }^{\circ}$. de Clínicas Veterinárias, Universidade Estadual de Londrina, UEL, Londrina, PR. E mail: vicky@uel.br

2 Médica Infectologista, Mestre em Medicina e Ciências da Saúde pela UEL, Prof ${ }^{a}$ Assistente da UEL, Coordenadora da CCIH da Irmandade Santa Casa de Londrina e do HU/UEL. E mail: carrilho@sercomtel.com.br

* Autor para correspondência
} 


\section{Introdução}

Os antimicrobianos, fármacos milagrosos do século XX, são um tema para debate interminável devido ao seu amplo uso na medicina humana, veterinária (BEOVIC, 2006) e agricultura (MARTINEZ, 2009). A resistência bacteriana aos antimicrobianos, um efeito colateral inevitável ao uso intenso destes fármacos (BEOVIC, 2006; GUARDABASSI; JENSEN; KRUSE, 2010) é motivo de preocupação mundial (VAN DEN BOGAARD; STOBBERINGH, 2000; NORMANNO et al., 2007) devido ao aumento da frequência de seres humanos com infecções graves em Unidades de Terapia Intensiva, com alto custo de tratamento e índice de mortalidade elevado (KAUSS et al., 2007). Atualmente é aceito que o principal fator de risco é o seu uso crescente (VAN DEN BOGAARD; STOBBERINGH, 2000; MOYAERT et al., 2006).

Os antimicrobianos são usados para prevenir ou tratar infecções bacterianas na medicina humana e veterinária (KÜMMERER, 2004; PHILLIPS et al., 2004; CARRILHO et al., 2007), mas também são adicionados às rações animais para promover crescimento e aumentar a eficácia alimentar (VAN DEN BOGAARD; STOBBERRINGH, 2000; NORMANNO et al., 2007). Estes promotores de crescimento (PC), principalmente glicopeptídeos como a avoparcina, foram usados extensivamente na Europa e vários autores sugeriram que tais antimicrobianos eram os responsáveis pelo desenvolvimento de Enterococus spp resistentes à vancomicina (VRE) em animais e posteriormente em seres humanos (VAN DEN BOGAARD; STOBBERRINGH，2000; MATEU; MARTIN, 2001, NORMANNO et al., 2007; REGULA et al., 2009), levando à proibição do uso de PC na Europa (PHILLIPS et al., 2004).

Em pesquisas conduzidas nos Estados Unidos, onde glicopeptídeos nunca haviam sido usados em animais de produção, observou-se que o VRE estava presente em pacientes e seres humanos sadios (MATEU; MARTIN, 2001). Este microorganismo também foi isolado de equinos e cães, raramente tratados com glicopeptídeos, que obviamente não receberam promotores de crescimento e que, no caso de equinos, não foram contaminados pela ingestão de carne (DEVRIESE et al., 1996). Nestes casos, a contaminação pode ter ocorrido pelas fezes de outros animais ou através de plantas contaminadas, mostrando que há outras maneiras da resistência disseminar-se (MATEU; MARTIN, 2001).

Após a introdução das fluoroquinolonas para uso em medicina veterinária nos anos 1990, houve evidência do aumento da resistência a essa classe de antimicrobianos em Salmonella spp isoladas de seres humanos, inclusive com similaridade genômica a amostras isoladas de animais (MATEU; MARTIN, 2001). Em crianças que nunca haviam recebido fluoroquinolonas, isolou-se Escherichia coli resistente a este antimicrobiano, sugerindo-se que o consumo de alimentos de origem animal era a fonte dessa resistência (MATEU; MARTIN, 2001).

Os cães e gatos também representam uma fonte potencial para a difusão de resistência antimicrobiana devido ao amplo uso destes agentes na rotina veterinária e ao contato muito próximo destes animais com os seres humanos, havendo estudos que relatam a transmissão de várias bactérias multirresistentes entre animais de estimação e seres humanos (GUARDABASSI; SCHWARZ; LLOYD, 2004; MOYAERT et al., 2006; UMBER; BENDER, 2009).

Em vista das controvérsias existentes e do problema que os antimicrobianos e a resistência a eles podem representar para a saúde pública, o objetivo nesta revisão é abordar o papel dos animais na transmissão de bactérias resistentes aos seres humanos e vice-versa e questionar a existência de outras fontes de resistência. 


\section{Uso de antimicrobianos em medicina veterinária}

Os antimicrobianos são usados em suínos, bovinos, caprinos, ovinos e aves de forma terapêutica, profilática e para aumentar o crescimento, produção e eficiência alimentar dos animais que geram produtos para o consumo humano, como carne, leite e ovos (VAN DEN BOGAARD; STOBBERINGH, 2000; TEUBER, 2001; UNGEMACH; MÜLLERBAHRDT; ABRAHAM, 2006), incluindo criações de peixes, camarões e moluscos (GUARDABASSI; JENSEN; KRUSE, 2010).

As justificativas para o uso de antimicrobianos em veterinária são a proteção do bem-estar animal, prevenção da propagação epidêmica de doenças infecciosas, melhora da eficácia da produção animal, prevenção da transferência de zoonoses de animais aos seres humanos, segurança dos produtos de origem animal e prevenção de doenças de origem alimentar; assim, os antimicrobianos são fármacos vitais em medicina veterinária e dificilmente podem ser substituídos se não existirem alternativas viáveis (UNGEMACH MÜLLER-BAHRDT; ABRAHAM, 2006).

Os antimicrobianos em veterinária são usados de quatro maneiras (SCHWARZ; KEHRENBERG; WALSH, 2001; GUARDABASSI; JENSEN; KRUSE, 2010):

1) terapêutica: com o objetivo de controlar uma infecção bacteriana existente,

2) metafilática: termo controverso, referindo-se ao uso com fins terapêuticos e profiláticos. Usada principalmente em animais de produção, onde grupos de 30.000 frangos de corte ou 100 suínos, por exemplo, recebem a medicação na água ou ração, após um animal apresentar um sintoma de uma doença infecciosa, com o objetivo de reduzir o número de animais doentes/mortos ou a quantidade de antimicrobiano necessário para tratar um grande número de animais sintomáticos.
3) Profilática: usada em indivíduos ou grupos. Em vacas leiteiras são usados antimicrobianos no fim do período de lactação pela via intramamária para prevenir mastite. Já a profilaxia cirúrgica é realizada da mesma maneira que na medicina humana, ou seja, é aplicado um antibiótico imediatamente antes do início do procedimento cirúrgico, para que níveis adequados do fármaco estejam atuando no momento da incisão cirúrgica (AIELLO et al., 2007; GUARDABASSI; JENSEN; KRUSE, 2010).

4) Promotor de crescimento em animais de produção: antimicrobianos são usados como suplemento alimentar, continuamente, em doses subterapêuticas.

As principais doenças dos animais de produção tratados com antimicrobianos são as gastrentéricas, respiratórias, cutâneas e reprodutivas (TEUBER, 2001; REGULA et al., 2009). No Reino Unido, o uso terapêutico em animais é três vezes maior que o uso como aditivo em rações; na Holanda, a quantidade de antimicrobianos usada como promotor de crescimento foi a mesma que para fins terapêuticos (VAN DEN BOGAARD; STOBBERINGH, 2000).

No gado leiteiro, as bactérias encontradas em mastites, os patógenos entéricos como Escherichia coli, Salmonella spp e os respiratórios como Pasteurella spp e Haemophilus spp (MULVEY et al., 2009) são os microorganismos que mais comumente requerem terapia antimicrobiana (MATEU; MARTIN, 2001). Podem ser citados como antimicrobianos mais usados nesta espécie amicacina, ampicilina, carbeniclina, cefalotina, florfenicol, gentamicina, sulfametoxazoltrimetoprima e tetraciclinas (SRINIVISAN et al., 2007).

Em equinos, os antimicrobianos são usados no tratamento de septicemia neonatal, infecções musculoesqueléticas, respiratórias, cutâneas, oculares, gastrintestinais e reprodutivas, além da profilaxia operatória (ROBINSON; SPRAYBERRY, 2009). Em levantamento realizado em um hospital 
veterinário universitário no estado do Colorado (EUA) entre 1994 e 2001, 54\% dos equinos hospitalizados receberam antimicrobianos, sendo prescrito o uso de penicilina/ampicilina em 39\% dos casos (DARGATZ; TRAUB-DARGATZ, 2004).

Em animais de companhia, os antimicrobianos são usados na prevenção e tratamento de doenças infecciosas, principalmente as infecções de pele, otite externa, infecções respiratórias, infecções do trato urinário, do trato gastrintestinal (GUARDABASSI; SCHWARZ; LLOYD, 2004), feridas traumáticas (PEREIRA; BAHR ARIAS, 2002) e na profilaxia cirúrgica (AIELLO et al., 2007; UMBER; BENDER, 2009). As classes de antimicrobianos usados em animais de companhia, em geral, incluem penicilinas, cefalosporinas, macrolídeos, lincosamidas, tetraciclinas, sulfas potencializadas, aminoglicosídeos e fluorquinolonas (PEREIRA; BAHR ARIAS, 2002; GUARDABASSI; SCHWARZ; LLOYD, 2004; BAHR ARIAS et al., 2008).

Em aves, os principais antimicrobianos usados são sulfonamidas, penicilinas, polipeptídeos, lincosamidas, cefalosporinas e quinolonas, enquanto que nos suínos utiliza-se tetraciclinas, sulfonamidas, cefalosporinas, fluorquinolonas e aminoglicosídeos (GUARDABASSI JENSEN; KRUSE, 2010).

$\mathrm{Na}$ aquicultura, os antimicrobianos são usados em larga escala em fazendas de criação de peixes e camarões, visando o combate às doenças bacterianas destes animais. Também o uso profilático é adotado, principalmente em países sem regulamentação para o uso destes fármacos (CARNEIRO et al., 2007), sendo as fluorquinolonas as mais utilizadas (COSTA et al., 2008). Entretanto, devido à grande diversidade no setor de aquicultura, existem ainda dados insuficientes sobre as quantidades utilizadas, a variedade de agentes empregados e a farmacocinética e farmacodinâmica em várias espécies (GUARDABASSI; JENSEN; KRUSE, 2010).

\section{Uso de promotores de crescimento}

O uso de PC iniciou-se a partir de 1940, quando se constatou que frangos tratados com tetraciclinas cresciam mais rápido que os não tratados com estes aditivos (PHILLIPS et al., 2004). Os antimicrobianos mais utilizados, atualmente ou no passado, como PC incluem macrolídeos (tilosina e espiramicina), polipeptídeos (bacitracina), glicopeptídeos (bambermicina), estreptograminas (virginiamicina), glicopeptídeos (avoparcina), quinoxalinas (carbadox e olaquindox), entre outros (BRUMANO; GATTÁS, 2009; GUARDABASSI; JENSEN; KRUSE, 2010).

Em 1998 foi proibido o uso da espiramicina, tilosina, virginiamicina e bacitracina, e a partir de 2008 proibiu-se o uso de todos os promotores de crescimento na UE. No Brasil, o Ministério da Agricultura Pecuária e Abastecimento (MAPA) vetou a utilização de antimicrobianos como tetraciclinas, cloranfenicol, furazolidona, nitrofurazona, sulfanamidas e avoparcina e algumas empresas suspenderam voluntariamente o uso de bacitracina, tilosina, virginiamicina e espiramicina visando manter a exportação de frangos para a UE (BRUMANO; GATTÁS, 2009).

Tais diretrizes estão de acordo com as recomendações da Organização Mundial de Saúde em 2000 e endossadas pela Organização das Nações Unidas para Agricultura e Alimentação e pela Organização Internacional de Epizootias em 2003 (GUARDABASSI; JENSEN; KRUSE, 2010).

Os PC parecem atuar através da alteração da microbiota e destruição de bactérias patogênicas do trato gastrintestinal dos animais de produção, resultando em melhor digestão dos alimentos e metabolismo dos nutrientes (PHILLIPS et al., 2004; BRUMANO; GATTÁS, 2009), o que é apoiado pelo fato que em animais livres de patógenos ocorre desempenho superior aos animais criados em sistemas convencionais, que por sua vez ao receberem PC apresentam desempenho próximo aos animais livres de patógenos (BRUMANO; 
GATTÁS, 2009). Entretanto, os benefícios dos PC podem ser minimizados, se não anulados, pela melhora nas condições de higiene e manejo (GUARDABASSI; JENSEN; KRUSE, 2010).

Outros promotores atuam suprimindo as doenças infecciosas, comprovado pelo fato de que após a proibição do uso de PC na UE, houve aumento da frequência de doenças infecciosas e da necessidade do uso de antibioticoterapia terapêutica (PHILLIPS et al., 2004). Embora os antimicrobianos possam atuar como PC e ajudar a manter a saúde do gado, existem desvantagens com o seu uso, como a seleção de genes resistentes na população de bactérias comensais ou mesmo nas bactérias patogênicas, que podem, então, ser transferidas aos patógenos humanos (MULVEY et al., 2009).

$\mathrm{Na}$ Europa, 30\% dos agentes antibacterianos eram utilizados como PC, entretanto nestes países, moléculas usadas de forma terapêutica em seres humanos e/ou animais não podiam ser usadas como PC. Apesar disso, muitos PC são análogos ou apresentam resistência cruzada com antimicrobianos terapêuticos (VAN DEN BOGAARD; STOBBERINGH, 2000), como por exemplo, o PC virginiamicina e o fármaco quinoprustina-dalfopristina indicado para o tratamento de infecções causadas por organismos Gram-positivos em seres humanos (VAN DEN BOGAARD; STOBBERINGH, 2000; PHILLIPS et al., 2004), o glicopeptídeo avoparcina e os antimicrobianos vancomicina e teicoplamina, e os macrolídeos com a eritromicina e claritromicina (SCHWARZ; KEHRENBERG; WALSH, 2001).

\section{Estimativa da quantidade de antimicrobianos utilizados em animais}

Estima-se que $50 \%$ dos antimicrobianos produzidos mundialmente sejam utilizados em seres humanos, sendo a outra metade empregada na profilaxia e tratamento de doenças em animais de companhia, extermínio de pragas na agricultura e também como promotor de crescimento animal
(VAN DEN BOGAARD; STOBBERRINGH, 2000; MATEU; MARTIN, 2001; MOTA et al., 2005; GUARDABASSI; JENSEN; KRUSE, 2010), incluindo a aquicultura (TEUBER, 2001; CARNEIRO et al., 2007).

Os antimicrobianos usados em animais pertencem essencialmente às mesmas classes de antimicrobianos usados em seres humanos. De acordo com informações sobre o consumo na União Européia em 1997, 3.994 toneladas (t) de antimicrobianos foram utilizadas de forma terapêutica em veterinária, sendo $2.294 \mathrm{t}$ de tetraciclinas, 424t de macrolídeos, 322t de penicilinas, 154t de aminoglicosídeos, $75 \mathrm{t}$ de sulfatrimetoprima e 43t de fluorquinolonas (SCHWARZ; KEHRENBERG; WALSH, 2001). As 182 toneladas restantes incluíram cefalosporinas, lincosamidas, polipeptídeos e nitrofuranos. A nitrofurazona e o cloranfenicol foram banidos da pecuária, mas ainda eram utilizados em animais de companhia.

Outras 1.599t foram usadas como PC, incluindo macrolídeos, estreptograminas e polipeptídeos. Porém, após o banimento da maioria dos PC na Europa, estes não eram mais compostos por antimicrobianos de uso terapêutico em medicina veterinária ou humana, incluindo as estreptograminas e os glicopeptídeos, não mais licenciados para uso em animais. As novas classes de antimicrobianos como glicilciclinas, cetolídeos e oxazolidinas deveriam ser usadas exclusivamente em medicina humana (SCHWARZ; KEHRENBERG; WALSH, 2001).

Em estudo realizado na Suíça, avaliou-se o uso de antimicrobianos em medicina veterinária nos anos de 2004/2005, sendo as penicilinas, cefalosporinas, aminoglicosídeos, tetraciclinas e sulfonamidas os mais usados em bovinos, suínos, equinos, ovinos e caprinos, enquanto penicilinas, cefalosporinas, tetraciclinas e sulfonamidas foram os mais usados em cães e gatos. Neste mesmo estudo, os antimicrobianos considerados de alta prioridade para seres humanos pela Organização Mundial 
de Saúde, como fluorquinolonas, macrolídeos e cefalosporinas de $3^{\mathrm{a}}$ e $4^{\mathrm{a}}$ gerações, foram usados em menor quantidade, totalizando $9 \%$ das prescrições (REGULA et al., 2009).

Em 2002, 17,5\% das vendas de produtos farmacêuticos na Europa para animais de companhia foi de antimicrobianos (GUARDABASSI; SCHWARZ; LLOYD, 2004). Neste período, animais de companhia, equinos e outras espécies não utilizadas para alimentação consumiram 37\% dos produtos farmacêuticos, sendo que os animais de companhia receberam $55 \%$ das cefalosporinas e $45 \%$ das fluorquinolonas usadas em todos os animais da Dinamarca, o que é preocupante quando se considera que existiam 1,2 milhão de cães e gatos, 23 milhões de suínos, 130 milhões de frangos e 1,2 milhão de bovinos (UMBER; BENDER, 2009), indicando antibioticoterapia excessiva em uma população pequena (MATEU; MARTIN, 2001).

No Chile, enquanto $10 \mathrm{t}$ de quinolonas são usadas na medicina humana por ano, quase $100 \mathrm{t}$ deste antimicrobiano são utilizadas na aquicultura (MARTINEZ, 2009), devido à doença de origem bacteriana pisciriquetsiose (GUARDABASSI; JENSEN; KRUSE, 2010). Na Noruega, estima-se que o uso de antimicrobianos na criação de peixes é de $2 \mathrm{~g} / \mathrm{t}$ produzida, enquanto em outros países europeus o uso estimado seja de 10 a $100 \mathrm{~g} / \mathrm{t}$.

Apesar da maioria dos países não monitorar a prescrição e uso de antimicrobianos em animais (UMBER; BENDER, 2009), principalmente os de companhia, o cenário deve ser semelhante em outros países (MATEU; MARTIN, 2001), agravado pelo fato que nestes animais são usados, também, antimicrobianos licenciados para uso humano, incluindo compostos de importância primária no tratamento de infecções em seres humanos (GUARDABASSI; SCHWARZ; LLOYD, 2004).

\section{O aumento da resistência antimicrobiana em animais}

Nos anos 1970 foi descrita a emergência de bactérias resistentes em animais devido ao uso clínico e não clínico dos antimicrobianos em veterinária, mas pouca atenção foi dada à possibilidade dessa resistência tornar-se um problema importante, pois os dados disponíveis sobre o assunto eram escassos (MATEU; MARTIN, 2001). Existem inúmeros exemplos do aumento da resistência aos antimicrobianos em veterinária, em diversas espécies animais, sendo que muitos dos microorganismos apresentam resistência aos antimicrobianos de uso humano, o que é preocupante, pois as bactérias isoladas podem ser reservatório de genes resistentes, com papel na disseminação desta resistência às bactérias patogênicas e comensais (SRINIVISAN et al., 2007).

No Canadá em estudo com 2.483 bovinos, constatou-se que 2,1\% veiculavam Escherichia coli resistente à cefoxitina, sendo que $74,5 \%$ destes possuíam o gene $b l a_{\mathrm{CMY}-2}$ similar ao encontrado em infecções hospitalares em seres humanos no mesmo período (MULVEY et al., 2009). Em vacas leiteiras com mastite por Staphylococcus aureus, detectouse resistência crescente ao longo dos anos, com aumento de $40 \%$ para $86 \%$ de resistência à penicilina e de $3 \%$ para $20 \%$ à gentamicina, havendo, inclusive, a presença de bactérias resistentes à cefalosporina e produtoras de $\beta$-lactamase (MATEU; MARTIN, 2001).

Nos Estados Unidos, observou-se alteração do padrão de resistência da Escherichia coli de vacas com mastite havendo resistência a dois ou mais antimicrobianos em diferentes combinações, sendo a maioria dos isolados resistente à ampicilina $(98,4 \%)$ e muitas à estreptomicina (40,3\%), sulfisoxazol $(34,1 \%)$ e tetraciclina $(24,8 \%)$. Com relação aos antimicrobianos de uso humano, constatou-se resistência à aztreonam $(97,7 \%)$, cefaclor $(89,9 \%)$ e cefuroxima $(22,5 \%)$ - todas foram sensíveis à ciprofloxacina (SRINIVISAN et al., 2007). 
Os resultados dos estudos são diferentes em vários países, e nem sempre o uso dos antimicrobianos e promotores de crescimento está relacionado à resistência aos antimicrobianos. Por exemplo, na União Européia, estudou-se a suscetibilidade antimicrobiana de isolados intestinais de Escherichia coli, Salmonella spp, Campylobacter spp e Enterococcus spp de frangos, suínos e gado da Alemanha, França, Itália, Irlanda, Reino Unido, Dinamarca, Espanha e Holanda, constatandose variação na resistência entre antimicrobianos, bactérias, hospedeiros e países. Observou-se resistência baixa ou ausente da Escherichia coli e da Salmonella spp a novos antimicrobianos como cefepima, cefotaxima e ciprofloxacina, usados em humanos com microorganismos multiresistentes, enquanto que resistência aos antimicrobianos mais antigos, como ampicilina, tetraciclina e sulfametoxazol-trimetoprima, mais utilizados em veterinária, foi alta. Nenhuma das 785 amostras de Enterococcus spp foi resistente à linezolida, antibiótico de uso humano, restrito a uso hospitalar, indicado em pacientes com bacteremia. Algumas amostras apresentaram resistência à ampicilina e vancomicina; a resistência à quinupristina/ dalfopristina variou entre zero e $83 \%$. Concluiu-se que a resistência a componentes essenciais usados para tratar seres humanos foi geralmente baixa ou ausente (DE JONG et al., 2009).

As consequências do uso de antimicrobianos em pequenos animais não diferem da medicina humana e a quantidade e padrão de uso determinam as taxas de desenvolvimento de resistência (RANTALA et al., 2004; CARRILHO et al., 2007), sendo que vários estudos retrospectivos na Europa e Estados Unidos reportam aumento na prevalência de resistência em diferentes bactérias isoladas de animais de companhia (GUARDABASSI; SCHWARZ; LLOYD, 2004). Programas de monitoramento nacional da resistência antimicrobiana geralmente não analisam os dados em cães e gatos na maioria dos países (GUARDABASSI; SCHWARZ; LLOYD, 2004; RANTALA et al., 2004), porém o interesse no estudo da resistência antimicrobiana em animais aumentou devido ao surgimento de bactérias multirresistentes, como Staphylococcus aureus resistente à meticilina (MRSA) em pequenos animais (GUARDABASSI; JENSEN; KRUSE, 2010).

Observa-se em geral aumento da resistência a antimicrobianos em pequenos animais, de acordo com o maior ou menor uso do produto: em Staphylococcus coagulase-positivo isolados de infecções da pele, orelhas e mucosa de cães no período de 1980-1996 no Reino Unido, houve aumento da resistência à penicilina de $69 \%$ para $89 \%$, enquanto a resistência à oxitetraciclina permaneceu constante em 40\% (GUARDABASSI; SCHWARZ; LLOYD, 2004). Na Finlândia, comparou-se 22 cães com desordens dermatológicas tratados com diversos antimicrobianos em relação a 56 cães não tratados, constatando-se que havia mais Staphylococcus spp multirresistentes no grupo tratado e que os isolados de Staphylococcus spp dos cães tratados eram mais resistentes à sulfametoxazol-trimetoprima, penicilina, e lincosamidas, porém a resistência à oxacilina foi rara (RANTALA et al., 2004). Neste mesmo estudo a resistência da Escherichia coli e Enterococcus spp foi baixa nos animais tratados e não tratados, não se detectando Enterococus faecium resistente à vancomicina, um antimicrobiano hospitalar de uso restrito (RANTALA et al., 2004).

Em Aracaju/SE se pesquisou a ocorrência de Staphylococcus spp em 55 amostras colhidas de otites de cães, constatando-se sensibilidade à teicoplanina (100\%), imipenem (100\%) e vancomicina (91\%), de uso hospitalar restrito a seres humanos. A sensibilidade foi menor à cefalexina $(89 \%)$, e amoxicilina/ácido clavulânico (89\%), sendo os antimicrobianos menos eficazes a neomicina (61\%), sulfa/trimetoprima (44\%) e clindamicina (16\%). Em 17\% dos isolados detectou-se Staphylococcus spp resistente à oxacilina (TUNON; SILVA; FAIERSTEIN, 2008).

Em 14\% das amostras oriundas de infecções respiratórias, oculares, uterinas e feridas de 
equinos na Dinamarca, obteve-se o isolamento de Staphylococcus coagulase- negativa (MOODLEY; GUARDABASSI, 2009). Em pequenos animais e equinos, assim como em seres humanos, as infecções pós-operatórias são uma complicação comum, aumentando o tempo de internamento, o custo do tratamento e a mortalidade (GUARDABASSI; SCHWARZ; LLOYD, 2004; AIELLO et al., 2007; MOODLEY; GUARDABASSI, 2009). As infecções nosocomiais tem sido reconhecidas crescentemente em medicina veterinária $\mathrm{e}$, assim como na medicina humana, os patógenos mais comumente identificados são os cocos Gram-positivos como espécies de Staphyloccoccus spp e Enterococcus, membros da família Enterobacteriaceae e bastonetes Gram-negativos não-fermentativos como Acinetobacter e Pseudomonas spp (AIELLO et al., 2007; UMBER; BENDER, 2009). Em estudo conduzido em um centro cirúrgico veterinário, bactérias multirresistentes Gram-positivas (como Staphylococcus spp e Streptococcus spp) e Gramnegativas (como Pseudomonas spp e Proteus spp), foram responsáveis por infecções hospitalares causando os mesmos problemas encontrados na medicina humana (AIELLO et al., 2007).

As infecções hospitalares mais comumente relatadas em seres humanos são as relacionadas às infecções por cateter, do trato urinário, respiratórias e do sítio cirúrgico (UMBER; BENDER, 2009). Em animais de companhia, as infecções do sítio cirúrgico são a forma mais comum de infecção (UMBER; BENDER, 2009) e os fatores relacionados às infecções nosocomiais em seres humanos estão se tornando comuns nos hospitais veterinários, como o uso de dispositivos invasivos, implantes ortopédicos, período de hospitalização prolongada, imunossupressão e uso indiscriminado de antimicrobianos (AIELLO et al., 2007; GARCIA et al., 2007; CARRILHO et al., 2007; BAHR ARIAS et al., 2008; UMBER; BENDER, 2009).

\section{Bactérias de Interesse Clínico}

\section{Bactérias Zoonóticas}

a) Gram-negativas

Muitas infecções alimentares em seres humanos são causadas por bactérias Gram-negativas, como Salmonella spp, Campylobacter spp e Yersinia spp, havendo, inclusive, a transferência de bactérias resistentes entre os próprios seres humanos (VAN DEN BOGAARD; STOBBERINGH, 2000).

\section{Salmonella spp}

As bactérias do trato intestinal contaminam as carnes no abate e os seres humanos infectam-se pelo contato direto com animais, fezes contaminadas ou, principalmente, pela ingestão de produtos de origem animal como carne e ovos (VAN DEN BOGAARD et al., 2000, PHILLIPS et al., 2004). Entretanto, os alimentos não são a única fonte de transmissão, pois os animais de fazendas podem transmitir a bactéria aos tratadores e veterinários e os animais de companhia aos seus proprietários; também o ser humano pode transmitir ao seu semelhante se os hábitos de higiene não forem adequados (PHILLIPS et al., 2004).

Os reservatórios de Salmonella typhimurium são primariamente os bezerros, mas ovelhas, cabras, suínos, aves e equinos também podem infectar-se, sendo que seres humanos e animais assintomáticos são comuns (VAN DEN BOGAARD; STOBBERINGH, 2000). Entretanto surtos epidêmicos de Salmonella spp virulenta ocorrem esporadicamente e o mesmo fagotipo com perfil idêntico de multirresistência é identificado em seres humanos e animais de produção (VAN DEN BOGAARD; STOBBERINGH, 2000).

Em equinos, Salmonella spp é um dos principais agentes envolvidos em casos de infecção hospitalar. Em geral, menos de 1,8\% de equinos tem Salmonella spp identificada em suas fezes e menos de $5 \%$ destes isolados são resistentes aos antimicrobianos testados. 
Entretanto, em equinos doentes hospitalizados, os isolados de Salmonella apresentam multirresistência a vários antimicrobianos testados (DARGATZ; TRAUB-DARGATZ, 2004).

Em animais de companhia as zoonoses são esporádicas e sua frequência não é facilmente documentada devido à dificuldade em reconhecer e validar esta transmissão. Entretanto $1 \%$ dos casos de salmonelose anualmente reportada nos Estados Unidos está associada aos animais de estimação, havendo relatos de ocorrência de surto de Salmonella typhimurium mutirresistentes em clínicas de pequenos animais em Idaho, Minnesota e Washington. Em todos os surtos, a doença se manifestou nos funcionários das clínicas e proprietários dos animais após a manifestação da doença em felinos, sendo os isolados idênticos nas duas espécies (GUARDABASSI; SCHWARZ; LLOYD, 2004). Na Holanda, em um estudo com 6.589 cães diarréicos, constatou-se a presença de Salmonella spp em $1 \%$ dos animais, dos quais $53 \%$ eram resistentes à cefalexina, $37 \%$ à tetraciclina e 14\% à amoxicilina-ácido clavulânico (GUARDABASSI; SCHWARZ; LLOYD, 2004).

Salmonella typhimurium multirresistente também já foi isolada de hamsters, camundongos e ratos e de crianças que lidavam com estes animais; acredita-se que estes animais sejam uma fonte pouco reconhecida de infecção para seres humanos (UMBER; BENDER, 2009). Rações de animais de companhia também podem atuar como veículo de transmissão para salmonelose nos animais e posteriormente nos proprietários. Em 2006 e 2007, 70 casos em seres humanos ocorreram por infecção com Salmonella schwarzengrund proveniente de ração canina seca (UMBER; BENDER, 2009).

\section{Campylobacter spp}

O Campylobacter jejuni e, menos frequentemente, $C$. coli, estão entre as principais causas de gastrenterite em países desenvolvidos (PHILLIPS et al., 2004), considerando-se a carne de frango crua ou mal cozida como a fonte mais importante de contaminação para seres humanos, sendo que a emergência desta bactéria resistente às fluorquinolonas em humanos na Holanda iniciouse após a introdução do uso da enrofloxacina em frangos (VAN DEN BOGAARD; STOBBERINGH, 2000). Entretanto, devido à descoberta de isolados resistentes às fluorquinolonas de carne de frango proveniente de países como o Canadá, Suécia e Finlândia, onde não são usados estes antimicrobianos, ainda existem controvérsias sobre a origem da resistência desta bactéria (PHILLIPS et al., 2004).

Outras fontes, como água não tratada, leite cru e contaminação cruzada de alimentos, também veiculam Campylobacter spp, assim como há outros reservatórios destas bactérias, que incluem aves selvagens, suínos, gatos, ovelhas e bovinos (CHABAN; NGELEKA; HILL, 2010).

Estima-se que $6 \%$ dos casos de campilobacteriose entérica possam ter origem de animais de companhia; alguns estudos controlados indicaram que possuir um animal era um fator de risco para esta infecção, especialmente em crianças (GUARDABASSI; SCHWARZ; LLOYD, 2004), o que foi reforçado pelos resultados de um estudo que identificou 14 espécies de Campylobacter em 58\% de cães sadios e 97\% de cães diarréicos (CHABAN; NGELEKA; HILL, 2010).

\section{Escherichia coli}

Trata-se de uma bactéria com muitos sorotipos encontrada no intestino de várias espécies animais, inclusive o ser humano; alguns sorotipos são especialmente patogênicos, podendo causar meningite, síndrome hemolítica, gastrenterite e infecção do trato urinário em seres humanos, além de doença gastrintestinal em animais como bovinos e suínos (PHILLIPS et al., 2004). Em hospitais veterinários, E.coli já foi encontrada como causadora de infecção hospitalar em cães internados em Unidades de Tratamento Intensivo (UMBER; BENDER, 2009). 
Em amostras fecais de perus e suínos constatouse transferência de amostras de Escherichia coli resistentes à ciprofloxacina entre os animais e os fazendeiros; o mesmo ocorreu com amostras resistentes à tetraciclina entre frangos e seres humanos (VAN DEN BOOGARD et al., 2000). Amostras causadoras de infecção do trato urinário em cães eram filogeneticamente relacionadas a $E$. coli patogênica extraintestinal de seres humanos (EXPEC); embora a transmissão direta não tenha sido documentada ainda, as fezes caninas poderiam ser uma fonte para a recontaminação de seres humanos (GUARDABASSI; SCHWARZ; LLOYD, 2004).

Em 51 amostras de E. coli isoladas de 2.483 bovinos de um confinamento no Canadá, encontrouse plasmídeos que conferem resistência à cefoxitina com padrão similar à encontrada em isolados humanos de amostras hospitalares (MULVEY et al., 2009). Em um estudo na Espanha, em isolados de fezes de frangos de corte, suínos, cães, touros, equinos, seres humanos e alimentos de origem animal, houve alta frequência de resistência ao ácido nalidíxico, ciprofloxacina e gentamicina de amostras dos frangos e alimentos (SÁENZ et al., 2001). Em isolados de E. coli provenientes de infecção do trato urinário, infecções pós-cirúrgicas e feridas de 10 cães internados em um hospitalescola na Austrália, foram identificadas bactérias com resistência mediada pelo plasmídeo bla ${ }_{\text {cmy-7 }} \mathrm{com}$ resistência à tetraciclina, enrofloxacina, ampicilina, sulfa-trimetoprima, ticarcilina, piperacilina e amoxicilina/ácido clavulânico, porém com sensibilidade à amicacina e imipenem (SIDJABAT et al., 2006).

Existem resultados variáveis quanto à origem da resistência antibiótica da E. coli no ser humano, pois isolados de E. coli de animais foram muito mais suscetíveis aos antimicrobianos do que amostras oriundas de humanos; em outra pesquisa realizada no Reino Unido, encontrou-se amostras de E.coli colhidas de roedores selvagens sem contato com o ser humano apresentando resistência à vários antimicrobianos (PHILLIPS et al., 2004), mostrando que a forma como a resistência desenvolve-se e é transmitida nos vários ecossistemas ainda não foi esclarecida.

\section{Staphylococcus resistente à meticilina}

O S. aureus resistente à meticilina (MRSA) é um problema de relevância em medicina humana, se constituindo em uma das principais causas de infecção em pacientes hospitalizados (GARCIA et al., 2007; CARRILHO et al., 2007); este microorganismo também está despontando como causa de infecção comunitária em pessoas sem fatores de risco para a ocorrência de infecção hospitalar (CAPOBIANGO et al., 2007; SASAKI et al., 2007; NORMANNO et al., 2007). Em seres humanos é causa comum de infecções cutâneas superficiais e invasivas, como septicemias/ bacteremias, pneumonia, osteomielite, infecção do sítio cirúrgico e endocardite (CAPOBIANGO et al., 2007; UMBER; BENDER, 2009), restando poucas opções terapêuticas contra este microorganismo (PELLISSON et al., 2010).

O gênero Staphylococcus engloba uma variedade de patógenos oportunistas de relevância variável em veterinária, sendo os mais importantes clinicamente o Staphylococcus aureus coagulasepositiva e os membros do grupo Staphylococcus intermedius, particularmente o Staphylococcus pseudointermedius (WEESE; DUIJKEREN, 2010). Uma propriedade importante deste gênero é sua capacidade de se tornar resistente à meticilina devido à presença do gene $m e c A$, o que torna esta bactéria resistente às penicilinas, cefalosporinas e carbapenéns (WEESE; DUIJKEREN, 2010).

Historicamente o MRSA fez o caminho inverso, ou seja iniciou como um problema em medicina e posteriormente, tanto o MRSA como o $S$. pseudointermedius resistente à meticilina (MRSP) emergiram como um problema significativo na área veterinária (WEESE; DUIJKEREN, 2010). O MRSA já foi detectado em animais de produção, 
aves, equinos, cães, gatos (SASAKI et al., 2007) e alimentos (WEESE; DUIJKEREN, 2010). O S. pseudointermedius, uma reclassificação do $S$ intermedius realizada por meio de características fenotípicas, foi descrito em 2005, em isolados de gato, cão, equino e papagaio, identificado, posteriormente, como MRSP (WEESE; DUIJKEREN, 2010).

Com o MRSA causando infecções comunitárias, os animais domésticos em contato próximo às pessoas acabaram infectando-se, o que trouxe consequências tanto para os animais como para o ser humano. A colonização dos animais foi maior entre os que visitavam hospitais ou conviviam com crianças (WEESE; DUIJKEREN, 2010). Cães e outros animais de estimação que convivem com seres humanos portadores podem, então, tornar-se colonizados com MRSA, e a falha em identificar estes animais pode resultar em recidiva de colonização e infecção humana (DE MARTINO et al., 2010). Em um paciente humano diabético, a infecção só foi eliminada após o tratamento do cão portador (GUARDABASSI; SCHWARZ; LLOYD, 2004).

Em Londres detectou-se MRSA em 17,9\% dos funcionários de um hospital veterinário e em $9 \%$ dos cães internados, sendo as amostras resistentes também às fluorquinolonas e relacionadas a isolados de hospitais humanos (LOEFFLER et al., 2005). Na Alemanha, 869 amostras provenientes de pequenos animais de uma faculdade de medicina veterinária foram estudadas, detectando-se MRSA em 18 cães, quatro gatos, uma cobaia, um coelho, uma tartaruga aquática, um morcego e um periquito (WALTHER et al., 2008). Assim, os veterinários que trabalham em grandes clínicas e hospitais devem estar atentos para o caráter nosocomial do MRSA, realizando a identificação em todas as espécies animais incluindo as exóticas, principalmente, nos casos de infecções em feridas (WALTHER et al., 2008).

Os primeiros relatos de MRSA causando infecção oportunista em equinos hospitalizados, como infecções de tecidos moles e de sítio cirúrgico, revelaram que estas infecções decorreram do contato com seres humanos colonizados; posteriormente, relatos em várias partes do mundo descreveram infecções como pneumonia, metrite, onfaloflebite, sinusite, infecção da corrente sanguínea, osteomielite, tenosinovite e mastite em equinos hospitalizados ou não, sendo a administração de antimicrobianos durante a hospitalização fator de risco para aquisição da bactéria (WEESE; DUIJKEREN, 2010). No Reino Unido, a MRSA parece estar presente na população equina em geral; na Itália foi isolada de $35,2 \%$ de equinos sadios, sendo que entre os seres humanos tratadores destes animais, 13,8\% eram portadores da bactéria (DE MARTINO et al., 2010).

Emanimais de produção foiidentificadoMRSAna Holanda, inicialmente em infecções diagnosticadas em seres humanos que trabalhavam em granjas de suínos e, posteriormente, em $23 \%$ dos trabalhadores sadios de granjas suínas, uma quantidade 760 vezes maior que da população em geral (WEESE; DUIJKEREN, 2010). Posteriormente, em fazendas e matadouros houve alta prevalência de colonização em suínos e trabalhadores e a infecção clínica foi rara, mas em outro estudo MRSA foi isolado de suínos com infecção de pele, do trato urinário, metrite, mastite e agalactia (WEESE; DUIJKEREN, 2010).

Menos informações estão disponíveis sobre MRSA em gado bovino, existindo relatos de isolamento de MRSA de vacas com mastite e colonização de $28 \%$ de vitelos na Holanda (WEESE; DUIJKEREN, 2010). Já na avicultura existem poucos relatos de infecção ou colonização por MRSA (WEESE; DUIJKEREN, 2010).

MRSA também foi identificado em produtos de origem animal. Em 1995 foi descrito um surto de MRSA de origem alimentar que causou a morte de cinco pessoas (NORMANNO et al., 2007). Na Itália o MRSA foi identificado em 3,75\% das amostras de leite bovino e queijo (NORMANNO et al., 2007), 
havendo grande preocupação com as toxiinfecções que algumas MRSA podem produzir (WEESE; DUIJKEREN, 2010). De 444 amostras de frango examinadas, apenas duas apresentavam MRSA, sendo a fonte da contaminação dos alimentos desconhecida, até que se constatou que o MRSA de alguns alimentos de origem animal provinha da manipulação por seres humanos portadores da bactéria na cavidade nasal, enfatizando a necessidade de melhor educação sanitária dos manipuladores de alimento (NORMANNO et al., 2007).

\section{c) Enterococos}

São bactérias comensais da microbiota intestinal de seres humanos e animais. Os enterococos multirresistentes se constituem patógenos de grande importância nas infecções nosocomiais em pacientes críticos (PHILLIPS et al., 2004). Os enterococos resistentes à vancomicina (VRE) emergiram como um problema mundial, com grande aumento da sua prevalência nos hospitais humanos (GUARDABASSI; SCHWARZ; LLOYD, 2004).

Em um estudo realizado em Portugal com fezes isoladas de cães e gatos, foram encontradas amostras de E. faecium, E. avium e E. faecalis, com 100\% de resistência ao ácido nalidíxico, cefoperazona e oxacilina, porém VRE não foi identificado (RODRIGUES et al., 2002). Entretanto há relatos da presença de VRE em animais de produção e de companhia da Espanha, Nova Zelândia e Estados Unidos, embora a vancomicina não seja utilizada na clínica de pequenos animais, sugerindo que o VRE tenha sido co-selecionado por outros antimicrobianos (GUARDABASSI; SCHWARZ; LLOYD, 2004). Recentemente na Europa, um paciente canino com uma ferida infectada apresentou E. faecium resistente à gentamicina e vancomicina (ABBOTT et al., 2009).

Desde o início da identificação de VRE no Reino Unido em seres humanos, relacionou-se o uso do PC avoparcina como desencadeador do VRE. Entretanto, existem outras fontes alternativas potenciais, como vegetais, roedores selvagens e texugos que também veiculam VRE, sugerindo que outras fontes, além dos animais de produção, possam estar envolvidas (PHILLIPS et al., 2004). Um exemplo é a agricultura, em que a vancomicina é um dos antimicrobianos utilizados em culturas vegetais (PHILLIPS et al., 2004).

Nos Estados Unidos, onde os glicopeptídeos não foram utilizados como PC, há grande incidência de VRE, provavelmente pela pressão seletiva exercida pelo amplo uso de antibioticoterapia em seres humanos. Na Europa, onde o uso de glicopeptídeos é menor, a infecção por VRE é menos frequente; entretanto, nos países da Europa onde o uso de glicopeptídeos é maior devido à ocorrência de MRSA, a incidência de VRE aumentou (PHILLIPS et al., 2004).

\section{O meio ambiente e a resistência antimicrobiana}

O uso intenso de antimicrobianos em hospitais, fazendas e na agricultura leva à liberação de dois tipos de resíduos em grande quantidade nos ecossistemas naturais: os antimicrobianos e os genes de resistência, o que pode influenciar a população de microorganismos destes locais (MARTINEZ, 2009). Alguns ecossistemas, como efluentes de hospitais humanos e fazendas, sofrem liberação constante de antimicrobianos, o que pode modificar a atividade metabólica da microbiota, sendo que alguns tipos de antimicrobianos não são biodegradáveis, permanecendo longo período no ambiente (KÜMMERER, 2004; MARTINEZ, 2009).

$\mathrm{Na}$ aqüicultura, os antimicrobianos adicionados à água podem levar à formação de resíduos que contaminam água, solo e consumidores. Relata-se a presença e persistência destes compostos nos peixes utilizados para consumo humano (CARNEIRO et al., 2007) e nos sedimentos ambientais, em quantidade suficiente para inibir crescimento bacteriano (KÜMMERER, 2004). 
Outra fonte de antimicrobianos nos tanques de peixes nestas fazendas é a utilização de dejetos de animais para adubação do plâncton que serve de alimento para peixes filtradores, como a tilápia. Assim, os excrementos de animais podem veicular resíduos de antimicrobianos ou bactérias resistentes aos antimicrobianos para o ambiente aquícola, que por sua vez podem se inserir na cadeia alimentar humana por meio do pescado contaminado e transferir genes de resistência às bactérias da microbiota indígena ou potencialmente patogênicas para seres humanos (CARNEIRO et al., 2007). Em um estudo com tilápias relata-se a presença de bactérias resistentes a todos os antimicrobianos testados, tanto no ambiente de criação como nos filés de tilápias, apesar de não haver uso dessas substâncias na piscigranja avaliada, o que sugere que a resistência aos antimicrobianos pode ser promovida e mantida por outros fatores que não o uso de antimicrobianos no meio aquícola (COSTA et al., 2008).

No solo é encontrado grande número de bactérias e fungos que produzem antimicrobianos, mantendo a dinâmica destas populações (KÜMMERER, 2004). É importante lembrar que, assim como os antimicrobianos originaram-se de microorganismos do meio ambiente, vários genes resistentes atualmente presentes em bactérias patogênicas já existiam em bactérias primitivas (MARTINEZ, 2009). Em ambientes primitivos como o núcleo profundo do gelo da Groelândia, águas não contaminadas da Antártida e subsuperfície terrestre, já foram isoladas bactérias com genes resistentes a antimicrobianos, o que mostra a ubiquidade destes microorganismos (MARTINEZ, 2009).

A resistência aos antimicrobianos é um problema do ecossistema em que os genes de resistência e bactérias resistentes migram constantemente entre os diversos meios e, em alguns estudos, comprovouse que a resistência nos animais originou-se das estações de tratamento de esgoto (SINGER et al., 2003). As atividades comerciais e o transporte entre países também justificam a presença de bactérias resistentes em populações remotas humanas e animais, incluindo espécies silvestres e aves que não receberam antimicrobianos (MARTINEZ, 2009).

\section{Considerações Finais}

A resistência aos antimicrobianos é inerente às bactérias, tendo sido identificada na medicina humana dois anos após a introdução da penicilina em 1941 (UMBER; BENDER, 2009). O MRSA foi detectado em 1961 em seres humanos, ano em que a meticilina foi comercializada (NORMANNO et al., 2007). Assim como o uso abusivo de antimicrobianos em seres humanos gera resistência nestes indivíduos, o abuso em animais gera a resistência nas bactérias dos próprios animais (SINGER et al., 2003).

Antimicrobianos são indispensáveis à manutenção da saúde humana e animal, mas não são substâncias milagrosas. O uso inapropriado de antimicrobianos em seres humanos em muitos países também é um problema de difícil controle, pois é possível a compra destes medicamentos em farmácias e supermercados sem prescrição médica (BEOVIC, 2006). Assim, estima-se que 20 a 50\% do uso de antimicrobianos em seres humanos e 40 a $80 \%$ em animais seja desnecessário ou altamente questionável (BEOVIC, 2006).

A noção de que a resistência aos antimicorbianos em seres humanos originou-se do uso de PC, sugerindo-se então que a eliminação do uso de antimicrobianos em animais seria uma estratégia viável, é muito simplista, pois não considera a repercussão à saúde animal e humana (SINGER et al., 2003; MARTINEZ, 2009), já que um exemplo dessa decisão, como o banimento do uso de antimicrobianos em animais de produção aumentou a incidência de doenças do gado bovino na Dinamarca entre 1999 e 2001 (MARTINEZ, 2009).

O relacionamento próximo que existe entre animais e o ser humano justifica que esforços coordenados e uma abordagem ecológica ampla sejam realizados (WEESE; DUIJKEREN, 2010), 
incluindo a redução da eliminação destes agentes nos esgotos dos hospitais, que deveriam ser tratados adequadamente (MARTINEZ, 2009).

Os profissionais de saúde devem reconhecer que a resistência aos antimicrobianos é um problema multifacetado e a solução provavelmente requer esforços ativos (UMBER; BENDER, 2009), com colaboração entre veterinários, produtores, médicos, autoridades de saúde e companhias farmacêuticas (MATEU; MARTIN, 2001). Para isso deve-se levar em consideração a epidemiologia das bactérias, a interação entre seres humanos e animais, o uso correto de antimicrobianos em todas as espécies e a aplicação de princípios gerais de controle de infecção (WEESE; DUIJKEREN, 2010). Devese, ainda, implementar medidas adequadas que diminuam a transmissão da resistência na cadeia alimentar como, por exemplo, práticas modernas de criação e abate de animais, manipulação e preparo adequado dos alimentos (SINGER et al., 2003).

O uso racional destes fármacos é imperativo (AIELLO et al., 2007; CARRILHO et al., 2007) e deve ser baseado no conhecimento dos agentes infecciosos por meio do isolamento bacteriano e uso de testes de sensibilidade antimicrobiana, além do uso destas medicações em doses corretas por tempo adequado (MATEU; MARTIN, 2001). A prescrição criteriosa de antimicrobianos deve ser alcançada pela educação continuada de veterinários e médicos, com esclarecimentos à população sobre a real indicação destes produtos (SINGER et al., 2003).

\section{Referências}

ABBOTT, Y.; KIRBY, B. M.; KARCZMARCZYK, M.; MARKEY, B. K.; LEONARD, F. C.; FITZGERALD, S. High-level gentamicin-resistant and vancomycinresistant Enterococcus faecium isolated from a wound in a dog. Journal of Small Animal Practice, Oxford, v. 50, n. 4, p. 194-197, 2009.

AIELLO, G.; BATTAGLIA, L.; BAHR ARIAS, M. V.; FREITAS, J. Determinação dos índices de infecção hospitalar em um centro cirúrgico universitário veterinário de pequenos animais. Acta Scientiae Veterinariae, v. 35, s. 2, p. 354s-356s, 2007.

BAHR ARIAS, M. V. B.; BATAGLLIA, L. A.; AIELLO, G.; CARVALHO, T. T.; FREITAS, J. C. Identificação da suscetibilidade antimicrobiana de bactérias isoladas de cães e gatos com feridas traumáticas contaminadas e infectadas. Semina: Ciências Agrárias, Londrina, v. 29, n. 8, p. 861-874, 2008.

BEOVIC, B. The issue of antimicrobial resistance in human medicine. International Journal of Food Microbiology, Amsterdam, v. 112, n. 3, p. 280-287. 2006.

BRUMANO, G.; GATTÁS, G. Implicações sobre o uso de antimicrobianos em rações de monogástricos. Revista Eletrônica Nutriti.me, Viçosa, v. 6, n. 3, p. 953-959, 2009.

CAPOBIANGO, J. D.; BELEI, R.; CARRILHO, C. M. D. M.; FERRARI, L. L.; GABOARDI, D. M.; PELISSON, M. Surto por Staphylococcus aureus em UTI neonatal com provável envolvimento de profissionais de saúde. In: CONGRESSO BRASILEIRO DE INFECTOLOGIA, 15., 2007, Curitiba. Anais... Curitiba: BJID, p. 25.

CARNEIRO, D. O.; FIGUEIREDO H. C. P.; PEREIRA JUNIOR, D. J.; LEAL, C. A. G.; LOGATO, P. V. R. Perfil de susceptibilidade de bactérias isoladas em diferentes sistemas de cultivo de tilápia-do-nilo (Oreochromis niloticus). Arquivos Brasileiros de Medicina Veterinária e Zootecnia, Belo Horizonte, v. 59, n. 4, p. 869-876, 2007.

CARRILHO, C. M. D. de M.; GRION, C. M. C.; BONAMETTI, A. M.; MEDEIROS, E. A. S.; MATSUO, T. Multivariate analysis of the factors associated with the risk of pneumonia in intensive care units. The Brazilian Journal of Infectious Diseases, Salvador, v. 11, n. 3, p. 339-344. 2007.

CHABAN, B.; NGELEKA, M.; HILL, J. E. Detection and quantification of 14 Campylobacter species in pets dogs reveals an increase in species richness in feces of diarrheic animals. BioMed Central Microbiology, London, v. 10, n. 73, p. 1-7, 2010.

COSTA, R. A.; HITZSCHKY, G.; SILVA, G. C.; SILVA, R. H.; VIEIRA, F.; SAMPAIO, S. S. Susceptibilidade "in vitro" a antimicrobianos de estirpes de Vibrio spp isoladas de camarões (Litopenaeus vannamei) e de água de criação destes animais provenientes de uma fazenda de camarões no Ceará - nota prévia. Brazilian Journal of Veterinary Research and Animal Science, São Paulo, v. 45, n. 6, p. 458-462, 2008. 
DARGATZ, D. A.; TRAUB-DARGATZ, J. L. Multidrugresistant Salmonella and nosocomial infections. Veterinary Clinics of North America-Equine Practice, Philadelphia, v. 20, n. 3, p. 587-60, 2004.

DE JONG, A.; BYWATER, R.; BUTTY, P.; DEROVER, E.; GODINHO, K.; KLEIN, U.; MARION, H.; SIMJEE, S.; SMETS, K.; THOMAS, V.; VALLÉ, M.; WHEADON, A. A pan-Europeian survey of antimicrobial susceptibility towards human-use antimicrobial drugs among zoonotic and commensal enteric bacteria isolated from healthy food-producing animals. Journal of Antimicrobial Chemotherapy, London, v. 63, n. 4, p. 733-744, 2009.

DE MARTINO, L.; LUCIDO, M.; MALLARDO, K.; FACELLO, B.; MALLARDO, M.; IOVANE, G.; PAGNINI, U.; TUFANO, M. A.; CATALANOTTI, P. Methicillin-resistant staphylococci isolated from healthy horses and horse personnel in Italy. Journal of Veterinary Diagnostic Investigation, Columbia, v. 22, n. 1, p. 77-82, 2010.

DEVRIESE, L. A.; IEVEN, M.; GOOSENS, H.; VANDAMME, P.; POT, B.; HOMMEZ, J.; HAESEBROUCK, F. Presence of vancomycin-resistan enterococci in farm and pet animals. Antimicrobial Agents and Chemotherapy, Washington, v. 40, n. 10, p. 2285-2287, 1996.

GARCIA, J. C. P.; FERREIRA FILHO, O. F.; GRION, C. M. C.; CARRILHO, C. M. D. M. Impacto da implantação de um guia terapêutico para o tratamento de pneumonia nosocomial adquirida na unidade de terapia intensiva em hospital universitário. Jornal Brasileiro de Pneumologia, São Paulo, v. 33, n. 2, p. 175-184, 2007.

GUARDABASSI, L.; JENSEN, L. B.; KRUSE, H. Guia de antimicrobianos em veterinária. Porto Alegre: Artmed, 2010. 268 p.

GUARDABASSI, L.; SCHWARZ, S.; LLOYD, D. H. Pets animals as reservoirs of antimicrobial-resistant bacteria. Journal of Antimicrobial Chemotherapy, London, v. 54, n. 2, p. 331-332, 2004.

KAUSS, I. A. M.; BONAMETTI, A. M.; GRION, C. M. C.; NUNES, L. B.; THOMAZINI, M. C.; CARRILHO, C. M. D. M.; CARDOSO, L. T. Q. Evaluation of the source of infection in patients with severe sepsis. In: Fourth International Symposium on Intensive Care and Emergency Medicine for Latin America. Critical Care, São Paulo, v. 11, p. 27, 2007. p. 27. Suplemento 3. Disponível em: <www.biomedcentral.com/ content/pdf/ cc5839.pdf>. Acesso em: 15 ago. 2011.

KÜMMERER, K. Resistance in the environment. Journal of Antimicrobial Chemotherapy, London, v. 54, n. 2, p. 311-320, 2004.
LOEFFLER, A.; BOAG, A. K.; LINDSAY, J.A.; GUARDABASSI, L.; DALSGAARD, A.; SMITH, H.; STEVENS, K. B.; LLOYD, D. H. Prevalence of methicillin-resistant Staphylococcus aureus among staff and pets in a small animal referral hospital in the UK. Journal of Antimicrobial Chemotherapy, London, v. 56, n. 4, p. 692-697, 2005.

MARTINEZ, J. L. Environmental pollution by antibiotics and by antibiotic resistance determinants. Environmental Pollution, Amsterdam, v. 157, n. 11, p. 2893-2902, 2009.

MATEU, E.; MARTIN, M. Why is anti-microbial resistance a veterinary problem as well? Journal of Veterinary Medicine Series B-Infectious Diseases and Veterinary Public Health, Berlin, v. 48, n. 8, p. 569-581, 2001.

MOODLEY, A.; GUARDABASSI, L. Clonal spread of methicillin-resistant coagulase-negative staphylococci among horses, personnel and environmental sites at equine facilities. Veterinary Microbiology, Amsterdam, v. 137, n.3, p. 397-401, 2009.

MOTA, R. A.; FREITAS, M. F. L.; PORTO, W. J. N.; SILVA, L. B. G. Utilização indiscriminada de antimicrobianos e sua contribuição a multirresistência bacteriana. Brazilian Journal of Veterinary Research and Animal Science, São Paulo, v. 42, n. 6, p. 465-470, 2005.

MOYAERT, H.; DE GRAEF, E. M.; HAESEBROUCK, F.; DECOSTERE, A. Acquired antimicrobial resistance in the intestinal microbiota of diverse cat populations. Research in Veterinary Science, London, v. 81, n. 1, p. 1-7, 2006.

MULVEY, M. R.; SUSKY, E.; MC CRACKEN, M.; MORCK, D. W.; READ, R. R. Similar cefoxitinresistance plasmids circulating in Escherichia coli from human and animal sources. Veterinary Microbiology, Amsterdam ,v. 134, n. 3-4, p. 279-287, 2009.

NORMANNO, G.; CORRENTE, M.; LA SALANDRA, G.; DAMBROSIO, A.; QUAGLIA, N. C.; PARISI, A.; GRECO, G.; BELLACICCO, A. L.; VIRGILIO, S.; CELANO, G. V. Methicillin-resistant Staphylococcus aureus (MRSA) in foods of animal origin product in Italy. International Journal of Food Microbiology, Amsterdam, v. 117, n. 2, p. 219-222, 2007.

PELLISSON, M.; LASSIE, F. S.; IMAZU, G.; CARRILHO, C. M. D. M.; GARCIA, J. C. P. Uso da tigeciclina em um Hospital Universitário. In: SIMPÓSIO INTERNACIONAL DE MICROBIOLOGIA CLÍNICA, 2., 2010, Florianópolis. Anais... Florianópolis: Sociedade Brasileira de Microbiologia, 2010. Disponível em: $<$ http://www.sbmicrobiologia.org.br/2SIMC/resumos/ R0257-1.html>. Acesso em: 15 ago. 2011. 
PEREIRA, A. M.; BAHR ARIAS, M. V. Manejo de feridas em cães e gatos. Revisão. Revista Clínica Veterinária, São Paulo, v. 7, n. 38, p. 33-42, 2002.

PHILLIPS, I.; CASEWELL, M.; COX, T.; DE GROOT, B.; FRIIS, C.; JONES, R.; NIGHTINGALE, C.; PRESTON, R.; WADDELL, J. Does the use of antibiotics in food animals pose a risk to human health? Journal of Antimicrobial Chemotherapy, London, v. 53, n. 1, p. 2852, 2004.

RANTALA, M.; LAHTI, E.; KUHALAMPI, J.; PERSONEM, S.; JÄRVINEN, A. K.; SAIJONMZAAKOULUMIES, L.; HONKANEN-BUZALSKI, T. Antimicrobial resistance in Staphylococcus spp., Escherichia coli and Enterococcus spp. in dogs given antibiotics for chronic dermatological disorders, compared with non-treated control dogs. Acta Veterinaria Scandinavica, Copenhagen, v. 45, n. 1-2, p. 37-45, 2004.

REGULA, G.; TORRIANI, K.; GASSNER, B.; STUCKI, F.; MÜNTENER, C.R. Prescription patterns of antimicrobials in veterinary practices in Switzerland. Journal of Antimicrobial Chemotherapy, London, v. 63, n. 4, p. 805-811, 2009.

ROBINSON, N. E.; SPRAYBERRY, K. A. Current therapy in equine medicine. 6. ed. St Louis: Saunders Elsevier, 2009. 1104 p.

RODRIGUES, J.; POETA, P.; MARTINS, A.; COSTA, D. The importance of pets as reservoirs of resistant Enterococcus strains, with special reference to vancomycin. Journal of Veterinary Medicine Series B-Infectious Diseases and Veterinary Public Health, Berlin, v. 49, n. 6, p. 278-280, 2002.

SÁENZ, Y.; ZARAZAGA, M.; BRIÑAS, L.; LANTERO, M.; RUIZ-LARREA, F.; TORRES, C. Antibiotic resistance in Escherichia coli isolates obtained from animals, foods and human in Spain. International Journal of antimicrobial Agents, Amsterdam, v. 18, n. 4, p. 353-358, 2001.

SASAKI, T.; KIKUCHI, K.; TANAKA, Y.; TAKAHASHI, N.; KAMATA, S.; HIRAMATSU, N. Methicillin-resistant Staphylococcus pseudointermedius in a Veterinary Teaching Hospital. Journal of Clinical Microbiology, Washington, v. 45, n. 4, p. 1118-1125, 2007.

SCHWARZ, S.; KEHRENBERG, C.; WALSH, T. $R$. Use of antimicrobial agent in veterinary medicine and food animal production. International Journal of Antimicrobial Agents, Amsterdam, v. 17, n. 6, p. 431437, 2001.

SIDJABAT, H. E.; TOWNSEND, K. M.; HANSON, N. D.; BELL, J. M.; STOKES, H. W.; GOBIUS, K. S.;
MOOS, S. M.; TROTT, D. J. Identification of blacmy-7 and associated plasmid-mediated resistance genes in multidrug-resistant Escherichia coli isolated from dogs at a veterinary teaching hospital in Australia. Journal of Antimicrobial Chemotherapy, London, v. 57, n. 5, p. 840848, 2006.

SINGER, R. S.; FINCH, R.; WEGENER, H. C.; BYWATER, R.; WALTERS, J.; LIPSITICH, M. Antibiotic resistance - the interplay between antibiotic use in animals and human beings. Lancet Infectious Diseases, New York, v. 3, n. 1, p. 47-51, 2003.

SRINIVISAN, V.; GILLESPIE, B. E.; LEWIS, M. J.; NGUYEN, L. T.; HEADRICK, S. I.; SCHUKKEN, Y. H.; OLIVER, S. P. Phenotypic and genotypic antimicrobial resistance patterns of Escherichia coli isolated from dairy cows with mastitis. Veterinary Microbiology, Amsterdam, v. 124, n. 3, p. 319-328, 2007.

TEUBER, M. Veterinary use and antibiotic resistance. Current Opinion in Microbiology, New York, v. 4, n. 5, p. 493-499, 2001.

TUNON, G.; SILVA, E. P.; FAIERSTEIN, C. C. Isolamento de estafilococcus multirresistentes de otites em cães e sua importância para a saúde pública. Boletim Epidemiológico Paulista, São Paulo, v. 5, n. 58, p. 4-7, 2008.

UMBER, J. K.; BENDER, J. B. Pets and antimicrobial resistance. Veterinary Clinics North America: Small Animal Practice, Philadelphia, v. 39, n. 2, p. 279-292, 2009.

UNGEMACH, F. R.; MÜLLER-BAHRDT, D.; ABRAHAM. G. Guidelines for prudent use of antimicrobials and their implications on antibiotic usage in veterinary medicine International Journal of Medical Microbiology, Stuttgart, v. 296, p. 33-38, 2006.

VAN DEN BOGAARD, A. E.; STOBBERINGH, E. E. Epidemiology of resistance to antibiotics. Link between animals and humans. International Journal of Antimicrobial Agents, Amsterdam, v. 14, n. 4, p. $327-$ 335,2000 .

WALTHER, B.; WIELER, L. H.; FRIEDRICH, A. W.; HANSSEN, A.; KOHN, B.; BRUNNBERG, L.; LÜBKEBECKER, A. Methicillin-resistant Staphylococcus aureus (MRSA) isolated from small and exotic animals at a university hospital during routine microbiological examinations. Veterinary Microbiology, Amsterdam, v. 127, n. 1, p. 171-178, 2008.

WEESE, J. S.; VAN DUIJKEREN, E. Methicillinresistant Staphylococcus aureus and Staphylococcus pseudointermedius in veterinary medicine. Veterinary Microbiology, Amsterdam, v. 140, n. 3, p. 418-429, 2010. 